\title{
Age as a Determining Factor in L1 and L2 Acquisition
}

\author{
Antonija Šarić \\ Josip Juraj Strossmayer University of Osijek, Faculty of Food Technology Osijek, \\ Kuhačeva 18, 31000 Osijek, Croatia \\ Lidija Obad \\ Josip Juraj Strossmayer University of Osijek, Faculty of Food Technology Osijek, \\ Kuhačeva 18, 31000 Osijek, Croatia
}

\section{Doi:10.5901/jesr.2015.v5n1s1p25}

\begin{abstract}
This paper deals with L1 and L2 acquisition and factors which inhibit or stimulate this acquisition. It is generally agreed that L1 acquisition is neurologically, psychologically and cognitively conditioned and there is a critical period for a morphosyntactic language acquisition. However, certain aspects of L1 development can extend far into adulthood. When considering L2 acquisition, special attention is paid to the critical period which extends to the age of nine due to neurological and biological factors. Cerebral flexibility enables direct language acquisition aspiring to achieve native speaker's standard regarding the phonological and morphological aspects and the access to Universal Grammar. Early language acquisition requires less cognitive effort supporting the idea that less is more. Some latest discoveries, however, dispute this claim arguing that brain plasticity is not lost at that age. Emphasis is also given to the exercise hypothesis relating to the idea that capacity for language learning remains lifelong provided the learners start language exercise at an early age. On the other hand, maturation state hypothesis advocates that capacity for language learning declines with maturation regardless the exercise. When discussing L2 acquisition and nativelike ultimate attainment three various hypotheses are taken into consideration. The first one claims that native speaker's level is achievable only by child starters. The second one supports the former hypothesis adding that it is possible not only to child starters but also to individual late starters. The third hypothesis disputes these claims stating that nativelike ultimate attainment cannot be achieved by any of those learners.
\end{abstract}

Keywords: L1, L2 acquisition, critical period, nativelike ultimate attainment, child and late starters

\section{Introduction}

The issue of possible existence of an age factor in language development is a topic which generates a great interest and encourages fierce debates. The study of the age factor stretches far back into history, though systematic research commenced in the 1960s. Thorough overviews of such research can be found in the works of David Singleton (2005), Singleton and Ryan (2004) Birdsong (1999), and Nikolov (2009). The reasons for emergence of further discussions on the age factor in language development are derived from both theory and practice. The theoretical side can be explained by the fact that there is an interaction between the limitation faced by adult students when acquiring language and the idea that language development is backed by special biological programming, whereas the practical side involves the assertion that young learners of the second language possess an advantage over the older ones. That assertion becomes a frequent topic when discussing about an optimal age to start second language learning at school (Singleton and Ryan, 2004).

What remains controversial in this light is the issue whether there is an exclusively neurologically dependent critical period after which language acquisition is not possible any more or is greatly hampered. It might be that after childhood, the ability of language acquisition gradually declines as a result of the interaction between neurological, cognitive, psychological and social factors.

\section{Critical Period for L1 Acquisition}

Studies of the critical period for first language acquisition are scarce, mostly due to the fact that only few children could not acquire their mother tongue naturally and hence the presence of such a critical period has often been researched 
based on the language of people who have suffered brain damage followed by aphasia. The above studies have facilitated the conclusion that brain damage appearing at an early age implies a higher probability of full recovery, i. e. when there is still a possibility of language development. Confirmation of the existence of such a critical period is provided by children who were deprived of normal childhood and thus of first language acquisition (Steinberg, Nagata and Aline, 2001, as cited in Medved Krajnović, 2010).

The story of a boy named Victor who lived in the first half of the $19^{\text {th }}$ century serves as an acknowledgement of a critical period for first language acquisition. At the age of 12, the boy showed up in the French village of Aveyron, walked on four legs and produced inarticulate sounds. The boy's upbringing was trusted to Dr. Itard who worked at the Institute for People with Hearing Impairment in Paris and who attempted to acquaint the boy with social and linguistic behaviour. The boy managed to get used to some social norms, but he never learned more than a few words while due to his short life, his inability of language acquisition has never been clarified. It is still unclear if his inability resulted from skipping the critical period for language acquisition or from poor raising conditions or from some other congenital disorder.

The story of a psychically and physically abused girl named Genie who was put in a dark room at the age of just 20 months and kept there by her father who would only enter the room to bring her the food or to empty the chamber pot to which she was attached to, is even more prominent. The father did not communicate with her at all but only growled at her and when she tried to get into any kind of contact with him, he would beat her. The girl was found in Los Angeles in the 1970s when she was 13 years old. After having been taught for four years, she acquired vocabulary typical for five year-olds, but she had problems with syntax. She spoke telegraphically and could not comprehend complex grammatical structures. Although there is more available information about Genie's childhood, one still faces the issue about the cause of the inability of development of normal language skills. Is it a result of a late exposure to language learning or a consequence of the brutal living conditions?

On the other hand, there are plenty of proofs that the first language development continues long after puberty. While researching the morphology of the first language of Dutch pupils aged from 7 to 17, Smedts (1988 as cited in Singleton and Ryan, 2004) revealed that his seven year old examinees were, in average, familiar with only $14 \%$ of the Dutch morphology, the 13-year olds knew only $51 \%$ of the rules in question and the 17 year old children were acquainted with more than $66 \%$ of these rules. In fact, some aspects of the development of the first language go deep into adulthood.

Singleton (1989) drew the conclusion that if a child is exposed to any language in normal circumstances, he/she adopts the language fairly fast following the universal developmental pattern. It implies that children say their first words at the age of one, they significantly expand their vocabulary when they are two, and use two words in combination, when they turn three, a rise in their syntactic complexity and development of functional morphemes is manifested and when they are five, their entire linguistic system is shaped.

\section{Critical Period for L2 Acquisition}

In 1959, Penfield and Roberts, shared the opinion in their work, entitled Speech and Brain Mechanisms, that children can acquire their second language more efficiently due to neurological and biological factors. They collected evidences which encouraged them to claim that "after the age of nine, for the purposes of learning languages, the human brain becomes progressively stiff and rigid." (Penfield and Roberts, 1959 as cited in Singleton and Ryan, 2004). They advocated the idea that children should be introduced to the second language early in life since "when languages are taken up for the first time in the second decade of life, it is difficult to achieve a good result because it is unphysiological" (Penfield and Roberts, 1959 in Singleton and Ryan, 2004).

In their opinion, the child's brain possesses certain capacity for language learning and there might be a biological clock therein. They proposed a limit of about nine years of age until which there is cerebral flexibility that enables direct learning through information input. These scientists also explained lower levels of language acquisition as a consequence of a late start of language learning. According to them, children begin to think analytically at the age of nine and learn the second language through the first one. While investigating cases which involved recovery after aphasia, Lundeberg (1967) noticed that the examined children quickly regained their speaking ability that was not the case with adults. He explained that according to the theory, brain cell lateralization begins approximately at the age of two and ends before puberty. This theory is supported by the brain plasticity hypothesis, namely, in case of an injury of the left hemisphere during childhood, the brain remains flexible, plastic enough, to let other parts take over the language function. As children grow up, this plasticity vanishes (Hyltenstam and Abrahamson, 2003).

However, Lundeberg (1967) thinks that adults can learn a foreign language as well, which does not deny the 
theory of the critical period since:

a) adults are privileged as they have already learned one language, which means that some fundamental principles do not have to be acquired later;

b) adults are mature in the cognitive context and good at learning the aspects of the second language via learning mechanisms which are generally well used by them and adolescents, defined as explicit learning;

c) adults were not able to reach the standard of native speakers, particularly in the area of pronunciation despite the cognitive maturity and great efforts.

A certain number of authors who do not necessarily embrace the concept of critical period laid down by Lenneberg support, nevertheless, the idea that post-puberty second language learning is more conscious and difficult. Krashen, Scarcella and Long (1979) disclosed the following conclusions on second language acquisition:

1) adults make more progress in the initial acquisition stages as far as morphology and syntax are concerned;

2) older children acquire language faster than the young ones (in the light of morphology and syntax);

3) children are superior to adults in the long run.

In the 1970s, the existence of a critical period for language acquisition was much discussed and resulted in opposing opinions, which is why Krashen, Scarcella and Long (1979) divided the studies into two groups:

a) the first group encompassed those studies which dealt with the early beginnings of language learning;

b) the second one with the conclusions related to ultimate attainment. In the end, the authors drew the conclusion that older learners acquire some aspects of language faster than the young ones in the beginning, but young learners (particularly children) soon catch up with the former and finally surpass them. Although the last conclusion does not specifically involve ultimate attainment (Long, 1990 in Hyltenstam and Abrahamsson, 2003), research shows that young learners can, though rarely, reach the level of native speakers, which is almost impossible regarding grown-ups.

Numerous studies of the linguistic competence of immigrants reveal that it is much better to be exposed to the second language at an early age (Asher and Garcia, 1969; Patkowski, 1980 in Hyltenstam and Abrahamsson, 2003; Johnson and Newport, 1989). Johnson and Newport (1989) offer two interpretations of the theory of the critical period:

a) the first theory was entitled Exercise Hypothesis. It suggests that people possess superior capacity for language acquisition at an early age and if this capacity is not exercised on time, it gradually disappears or declines as individuals get older. If it is used, other language skills stay intact.

b) the second theory was called Maturational State Hypothesis. In line with this theory, people have superior capacity for language acquisition which disappears or declines with the process of maturation. The two theories represent different implications of the age factor in second language acquisition. According to the Exercise Hypothesis, learners who were not in touch with the first language during their childhood are not capable of acquiring the second language later on. However, if they acquire the first language in their childhood, their capacity for second language acquisition should not be impaired and is expected to be exercised at any age or in other words, children and adults are equal when it comes to second language acquisition and thus age does not matter in this context.

On the other hand, the Maturational State Hypothesis propagates that there is something extraordinary about the development of the child's brain that enables children to adapt to the acquisition of the first or second language. It also assumes the standpoint that the capacity for second language acquisition declines regardless of its exercise. In compliance with the latter hypothesis, age does matter in terms of second language acquisition. Both hypotheses can be interpreted if ones take into account the initial level concerning second language acquisition or ultimate attainment of learners of different ages and the capacity of acquiring various linguistic domains, which declines by time. According to the aforementioned, adults advance more rapidly at the initial language acquisition levels (Krashen, Long and Scarcella, 1979) while children catch up with the grown-ups in the end (Singleton, 1989).

The capacity for second language acquisition that declines over time can be observed through the morphological, phonological and syntactic domain. Johnson and Newport (1989) investigated the syntactic competence of Korean and Chinese children aged 3 to 39 by assessing their grammatical accuracy to evaluate the attainment of English as the second language with respect to their different age of arrival in the United Stated of America. The authors agreed that the syntactic performance of learners drops with the age of arrival in a foreign country, revealing a sharp decline between 14 and 16 years of age while children who came to America between three and seven years of age achieved results at the native speakers' level. Using a sample of 23 Chinese learners of English as the second language, who came to the USA at the age from 18 to 38, Johnson and Newport (1991) studied the acquisition of linguistic universals. The results disclosed that linguistic universals became less accessible to learners as they get older. Furthermore, the authors share 
the opinion that the changes occurring between childhood and adulthood have an effect on all the aspects of grammar acquisition, including the access to the Universal Grammar.

Regarding the morphological domain, Harley (1986) studied the level of acquisition of the French verb system in Canada using two groups of learners after 1000-hours language course and the data were collected by means of interviews and translation exercises. According to Harley, neither group managed to completely master the verb system, but the older groups achieved poorer results, demonstrating that the ability of second language acquisition declines even in the morphological domain. With respect to the phonological domain, Oyama (1976 in Dong and Ren, 2013) researched the accent of 60 immigrants to America aged between 5 and 18 rated by the native speakers. They concluded that children who moved to America at an early age did not have a foreign accent unlike those who were older than 12 when they came to the USA, which proves that the phonological competence of second language acquisition deteriorates by time as well. Second language acquisition (from the viewpoint of the initial level of acquisition or as ultimate attainment) depends on the early beginning of learning. The loss of the acquisition competence during the critical period gives relevance to the Maturational State Hypothesis, i. e. age influences second language acquisition. The research conducted by Johnson and Newport has remained dominant with respect to the limitations of maturation and critical period.

Concerning the age factor and second language acquisition, Bley-Vroman (1988, as cited in Medved Krajnović, 2010) offered a fundamental difference hypothesis, according to which adults acquire second languages in a way different from that of children, i. e. children unconsciously take advantage of the congenital structure of the Universal Grammar, whereas adults apply their knowledge of the first language (mother tongue) to utilize general learning mechanisms, i. e. their analytical skills while considering the organization of the second language. Accordingly, adult learners possess two privileges - the native language and general problem-solving ability which supplement each other or better to say, the native language opens up a path to the Universal Grammar and the general problem-solving ability is activated in analysing second language data, though this cooperation cannot compensate for the loss of the Universal Grammar, which is at hand to children. In order to clarify the age factor in second language acquisition, Felix (1985, as cited in Dong and Ren, 2013) developed a competition model, according to which, children's language learning is guided by a language-specific cognitive system, whereas adults apply their cognitive problem-solving system. These two systems compete. Newport (1990) defended the assumption less is more, which suggests that in case of early, natural exposure to a second language, investment of less conscious and cognitive efforts guarantees more success. Nevertheless, limited time and a need for structured learning (school environment) encourage adults and older children to learn more efficiently due to their explicit analytical skills. In terms of teaching efficiency, Moyer (2004) focuses on learning methods, having an emphasis on communication, since learners deem the same methods as being the most relevant, which is not the case with grammatical and translation exercises that lead to a delay of speech.

DeKeyser (2000) surveyed 57 English learners aged from 1 to 40 who were Hungarians and residents of the USA for 10 or more years. DeKeyser's test included 200 sentences; a few original sentences were deleted or amended while some supposedly difficult structures to the Hungarian examinees were added. Along with a grammatical assessment test, there was a linguistic competence test. This study was aimed at challenging the fundamental difference hypothesis (Bley-Vroman, 1988, as cited in in Medved Krajnović, 2010). Similar to the research conducted by Johnson and Newport (1989), DeKeyser's investigation did reveal significant correlations between the tests and variables such as length of stay, years of education or the age when the test was taken; there was only one negative correlation between the age and grammatically judgement tests. All children aged 16 or younger resolved correctly 180 out of 200 sentences (except a person who found solutions for only 170 sentences) while the score of most of the adult examinees (16 years of age or older) was below 180 points. However, it came to an overlap between these two groups; six examinees in the older groups had a relatively high score (above 175) and three of them exceeded the 180-point threshold. Such a score was derived, in DeKeyser's view, from the significant correlation between the results achieved at the grammatically judgement tests and the results accomplished at the general linguistic ability tests. The group with children aged 16 or less did not disclose any correlation between the grammatical competence and general linguistic ability. In other words, adult examinees with excellent results, similar to those of children who were exposed to the language at an early age, were characterized by a relatively high verbal-analytical competence, which facilitated their acquisition of the second language through an explicit overview of grammatical rules. In addition, DeKeyser's (2000) research showed that some structures are less prone to the age factor, which can be explained by means of perceptive prominence or in other words, the less prominent morphological structure, the less vulnerable it is to the age factor. Although DeKeyser's research is viewed as a consolidated version of Johnson and Newport's study (1989), it still involves certain flaws. One of them refers to the fact that the assertion that only adult learners with a high verbal competence can match children is not completely true 
since one out of three grown-ups did not have a high score at the general linguistic ability test. Likewise, since none of the native speakers served as a research control group, it is hard to compare the obtained results with native speakers' competence.

Hyltenstam and Abrahamson (2000) think that students who start learning a second language at an early age differentiate from native speakers and claim that there is no person who started learning a second language as a beginner and achieved the characteristics of native speakers regarding all linguistic aspects.

Today there are few scientists who deny the long-lasting advantage of children who start acquiring a second language as small children (Krashen, Long and Scarcella, 1979; Long, 1990). Yet, there are some discrepancies about the issue if this fact is to be explained by biological factors or limitations imposed on a learner together with maturational or socio-psychological factors. Most controversies on the issue of the critical period arise due to Lenneberg's (1967) original formulation of the critical period:

Automatic acquisition from mere exposure to a given language seems to disappear (after puberty), and foreign languages have to be taught and learned through a conscious and laboured effort. Foreign accents cannot be overcome easily after puberty. However, a person can learn to communicate at the age of forty. This does not trouble our basic hypothesis. (p. 176)

Indeed, the central place in the original formulation of the critical period is taken by the possibility of language acquisition up to the native speakers' level. Several scientists have lately stressed the fact that the hypothesis on the critical period and limitation of the maturational state relate to the capacity for language acquisition at the native speakers' level (Birdsong, 1999; Long, 1993 in Hyltenstam and Abrahamsson, 2003). Studies on the limitation of maturation or of the critical period have enticed the issues related to Lenneberg's fundamental concepts. At least three different theories which set ground for the researched issues can be considered. These are:

a) The first theory completely coincides with Lenneberg's theory and is focused on a language ability acquisition similar to that of native speakers, namely, simply through exposure to a second language. In this case, the hypothesis on the critical period should be regarded as groundless if this ability similar to native speakers' is found in learners, who start acquiring a language beyond a certain age limit, irrespective of the acquisition mode.

b) The second theory also deals with the respective age and ultimate language attainment and suggests that young learners outrank the older ones, which is witnessed by the final results with respect to ultimate attainment, even though older students sometimes reach the attainment level higher than that of the young ones under the same conditions.

c) According to the third theory, young learners are generally better at language acquisition than their older colleagues. The theory should be deemed as unfounded if older students are better than the young ones according to a success measurement in a particular area under the same learning conditions (Snow and Hoefnagel-Höhle, 1978 in Hyltenstam and Abrahamsson, 2003). While describing this theory, studies on ultimate attainment were neglected, which implies abilities similar to those of native speakers.

If acquisition of a second language vastly results from conscious efforts, i. e. learning in formal circumstances, the advantages of an early onset are either not recognized or it may be stated that they depend both on the age and many other factors (Nikolov 2009). Therefore, the ultimate success in foreign language learning is attributed to the interaction of a number of factors - motivational, interlingual, educational, generally cognitive and affective, e. g. a positive attitude towards all novelties and a low level of linguistic-cultural identity (Singleton 2001 in Medved Krajnović, 2010). Moyer (2004) also stressed that age is connected with socio-psychological factors such as motivation intensity, personal motivation, satisfaction with the achievement and personal fluency assessment. Later exposure to a language is characterized not only by stronger personal and professionally-oriented motivation but also by weaker satisfaction and lower fluency assessment and more intense aspiration to the native speakers' accent.

Hyltenstam and Abrahamsson (2003) substituted the concept of the critical or sensitive period for language acquisition with the concept of maturational period. They elaborated a model dealing with the role of the age of onset $(\mathrm{AoA})$ of language acquisition, which reveals the interdependence of maturation factors, socio-psychological influences and the influence of practice. This involves the possibility of natural use of language and the possibility of conscious efforts of an individual to improve their own knowledge of a language. In compliance with these authors, maturational or neurological-cognitive factors have the key role in the successfulness of language acquisition all the way to adolescence, while later in life the major role is played by socio-psychological factors and the language practice. In addition, the authors think that the ability of language acquisition gradually declines immediately after the birth and that foreign language speakers, no matter if they started to acquire a language at an early or late stage of life, can never reach the 
native speakers' competence at all levels. Considering the importance given to maturational factors in language acquisition by the aforementioned authors, the role of the first language in second language acquisition is extremely important, since second language acquisition at later stages of life is hardly possible due to maturation limitation. Moyer (2004) investigated the role of age and maturation. The research results demonstrated that the age effects are not equally prominent during different ages of onset of the second language learning, i. e. around 15 years of age, other factors play an important role in language acquisition since certain neurological changes are stabilized in puberty.

There are a growing number of studies showing that even individuals who start acquiring a second language after puberty can also reach a very high level of linguistic and communication ability. The first of such studies was published by Coppieters (1987 in Hyltenstam and Abrahamsson, 2003) who gave syntactic and semantic assessment tests to 21 adult learners of French as a foreign language, followed by an oral interview. However, although the examinees were preliminarily characterized as native speakers and although they answered the questions related to syntactic-semantic assessment correctly, their general score did not match the score of native speakers since the recorded interviews discovered mistakes in the structures resolved in the assessment exercises. Birdsong (1992 in Hyltenstam and Abrahamsson, 2003) made a replica of Coppieters' research using strict criteria for selection of examinees and realized that 15 out of 20 examinees, i. e. learners who started learning French as a foreign language, accomplished the same score at demanding grammatically judgement tests as native speakers.

Ioup, Boustagui, El Tigi and Moselle (1994 in Hyltenstam and Abrahamsson 2003) observed Julie, a talented British woman who moved to Cairo at the age of 21 (she had never learned Arabic before), married an Arab man and worked as an English teacher at school. At the time of the research, she had lived in Cairo for 26 years. The same authors kept track of Laura, an exceptionally talented American who had learned Arabic at various universities and in various countries before coming to Cairo, and during the performance of the research had been married to an Egyptian for already 10 years. What makes this research different from other similar studies is an extremely large number of measuring instruments which involved some highly demanding tasks. The examiners rated the women's oral production, the ability of their differentiation of dialects and their grammatical competence (translation, grammatically judgement tests, anaphoric interpretation). The research disclosed that both Julie and Laura accomplished better results at dialect differentiation tests than some native speakers (Julie had somewhat better score than Laura did). At the oral production tests, both women were graded as native speakers by most examiners (native speakers of Arabic and teachers of Arabic as a foreign language) and at the grammatical intuition tests, both examinees achieved a high score (although slightly below that of native speakers). In other words, the differences between Julie and Laure and other native speakers were negligible. Ioup Boustagui, El Tigi and Moselle (1994 in Hyltenstam and Abrahamsson, 2003) assumed that if there are exceptions in the critical period, the supposed neurocognitive differences do not occur in an ordinary way, although it is not clear if the usual acquisition manner keeps being functional or if there is an alternative system which substitutes the former.

Hyltenstam (1992 in Hyltenstam and Abrahamsson, 2003) examined the grammatical and lexical performance of 24 advanced examinees - Spanish and Finnish learners of Swedish aged 17-18 (their teachers did not immediately recognize them as non-native speakers). Out of 24 examinees, 16 of them started learning the second language when they were six years old or younger and 8 of them were eight years old or older. The examinees were bilingual and they actively used both languages. The group of 12 native Swedish speakers served as a control group and also participated in testing. The examinees were asked to orally retell four texts and to write an essay in Swedish. Even though the analysis of mistakes revealed their low frequency, the control group made 1-10 mistakes, the group of examinees who started learning the language at the age of six or earlier made 1-23 mistakes. In other words, the results of the 'older' group did not coincide with those of the native speaker group, whereas the results of the 'younger' group matched the results of both groups. Hyltenstam (1992 in Hyltenstam and Abrahamsson, 2003) concluded that the age of 6 to 7 is extremely important for differentiating the language acquisition of native speakers from the acquisition similar to that of native speakers. Considering that the group of younger students did achieve results similar to that of native speakers, it is assumed that an early age of onset may have a vital role in language acquisition although it is not a sufficient condition for the native speaker-like language acquisition.

Other studies on second language acquisition at an early age prove that there are differences between non-native speakers, who have almost reached the level of native speakers, and these differences referred to application of specific structures or to the scope and quality of vocabulary. The referring flaws are not immediately noticeable, but they can be traced in linguistic research results. Hene (1993 in Hyltenstham and Abrahamson, 2003) analysed several aspects of the vocabulary of 24 children aged 10-12 who were adopted by Swedish families at the age between three months and six years. The results revealed some differences in the comprehension of some frequent words and phrases, which appear 
in the curriculum and include local prepositions and lexical explanations expressed by synonyms and paraphrases.

Similar results were obtained by Butler (2000 in Hyltenstam and Abrahamsson, 2003). The author explored the knowledge of Chinese learners of English as a second language. The examinees were put into three groups (the first group - those who were first exposed to the language aged from 3 to 5 , the second group - between 5 and 10 , the third group - between 10 and 15) and there was one more group of native speakers. After applying a grammatically judgement test, it was concluded that the first group (those who got in touch with the language aged 3-5) achieved the best results, but these were still fairly below those of the native speakers. The first group was followed by the second group while the scores of the third group were the poorest (those who were exposed to language aged 5-10). Taking into consideration Butler's (2000, Ekberg, 1998; Hene, 1993 in Hyltenstam and Abrahamsson 2003), Hyltenstam's and Abrahamson's (2003) studies who explored second language acquisition, one can assume that they overlap with the studies on first language acquisition. It means that even the shortest delay in the age of onset does have an effect on ultimate attainment. Bearing in mind all the aforementioned, the outcome of the studies indicate that there is only a small number of learners who possess a potential for reaching the native speakers' level in one of the areas of the second language and such learners are deemed either highly motivated (Moyer, 1999 in Hyltenstam and Abrahamsson, 2003) or individuals with a high language learning ability (DeKeyser, 2000; Harley and Hart, 1997 in Hyltenstam and Abrahamsson, 2003).

Harley (1986) concluded that the successfulness of language acquisition is subject to a number of factors such as the level of cognitive maturity, motivation, exposure to a second language and the possibility of its active use, adding also that all these factors get into active interaction with the age of learners and obviously appear in connection with various levels of the language system. For instance, Harley emphasized that neurological factors, which do not have to be necessarily bound to language, but they can be more general such as the aging process in which it comes to decrease and deterioration of numerous neuron connections in the network of the brain nervous system, contribute to a diminished ability of all forms of learning and hence the language.

Besides the critical period, there are four types of factors which might be responsible for the impact of the age of onset of language learning. These are motivational, linguistic, educational and general cognitive factors (Singleton and Ryan, 2004). Motivational factors are linked with the issue of language domination. Late comers to the second language environment frequently come into contact with their mother tongue and accordingly, restrain their contacts with the second language, which can be interpreted by their wish for avoiding isolation and/or the wish for retaining a particular language-cultural identity. On the other hand, the children's affective filter is lower or in other words, a child's feelings towards everything related to second language acquisition are more positive than the feelings of adults and thus become a smaller drawback to acquisition of new information, knowledge and skills.

Regarding the linguistic factors, the time spent in the country where the target language is in use and the time spent with native speakers, have turned out to be the main determinant of the pronunciation quality of a second language (Riney and Flege, 1998 in Singleton and Ryan, 2004).

As far as the educational dimension is concerned, Bialystok and Hakuta (1999 in Hyltenstam and Abrahamsson, 2003) suggested that existence or a lack of second language writing skills can appear as a basis for second language competence and observed that immigrants who migrate at a young age have mostly well-developed writing skills - due to their schooling experience - while those who migrate as late comers do not have such a good opportunity to develop these skills.

Finally, in terms of the cognitive factors, Bialystok and Hakuta (1999 in Hyltenstam and Abrahamsson, 2003) stressed a regression in areas such as task completion under pressure, taking risks, establishment of long-term memory codes and the ability of memorizing details.

Taking into account the age of onset and ultimate attainment, the previous results might be summed up in the following way:

a) The native speakers' competence can only be attained by early learners, which is shown in Figure 1. 


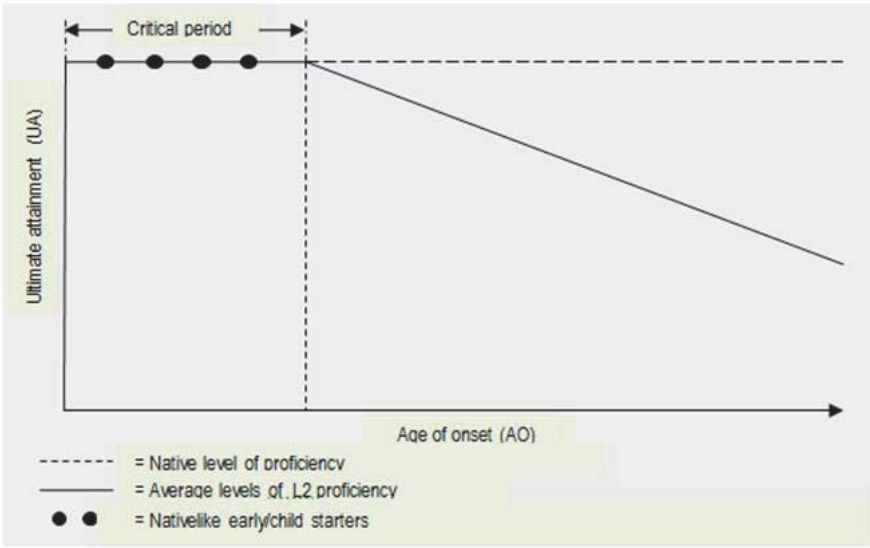

Figure 1. Observations of nativelike ultimate attainment in early starters only "Maturational Constraints in SLA" by K. Hyltenstam and N. Abrahamsson, 2003, p. 567. From The Handbook of Second Language Acquisition by Long, M. H. , 2003, Oxford, UK: Blackwell Publishing Ltd.

These data are based on the studies which suggest that the average attainment of young learners is similar to that of native speakers and that it negatively correlates with the age (Johnson and Newport, 1989; Patkowski, 1990 in Hyltenstam and Abrahamsson, 2003). The above results are explained by the biological effects of the critical period theory (DeKeyser, 2000; Johnson and Newport, 1989; Patkowski, 1990 in Hyltenstam and Abrahamsson, 2003). The alternative interpretation attributes it to identity, motivation, input, cognition, formal learning and other social conditions.

b) The native speakers' competence can be attained by early learners and by only few late learners as shown in Figure 2.

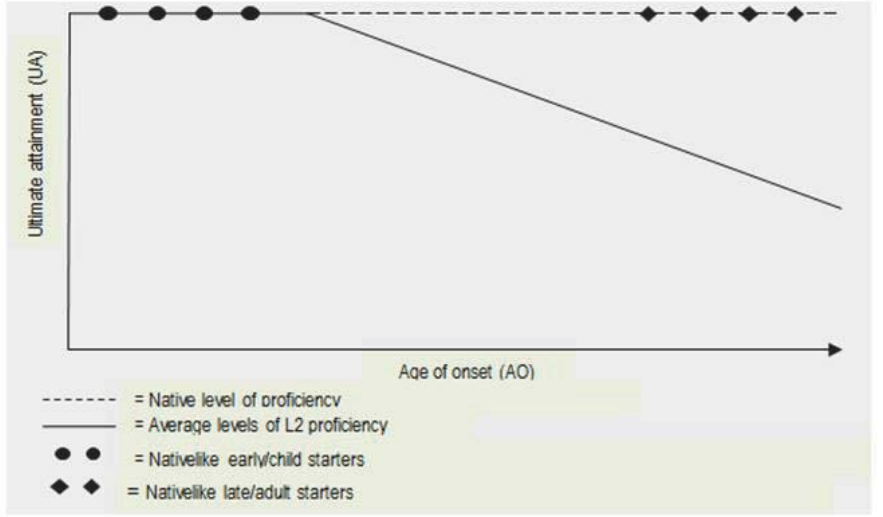

Figure 2. Observations of nativelike ultimate attainment in early starters and individual late starters. "Maturational Constraints in SLA" by K. Hyltenstam and N. Abrahamsson, 2003, p. 568. From The Handbook of Second Language Acquisition by Long, M. H. , 2003, Oxford, UK: Blackwell Publishing Ltd.

This theory is based on the research proving that there are exceptionally successful students who started learning a language late in life, but managed to reach the native speakers' level (Birdsong, 1992; Bongaerts, 1999; Moyer, 1999; White and Genesee, 1996 in Hyltenstam and Abrahamsson, 2003). The first explanation of this theory is that there is no biologically dependent critical period and that learners of any age can reach the native speakers' level (Birdsong, 1992; White and Genesee, 1996 in Hyltenstam and Abrahamsson, 2003). The second explanation says that despite the existence of a biologically dependent critical period, there are some late learners who can exceed the expectations of the critical period hypothesis compensating their late age of onset with a great talent (DeKeyser, 2000; loup et al, 1994 in Hyltenstam and Abrahamsson, 2003), high motivation (Bongaerts, 1999, 2000; Moyer, 1999 in Hyltenstam and 
Abrahamsson, 2003), formal education and input (Bongaerts, 1999 in Hyltenstam and Abrahamsson, 2003).

c) The native speakers' competence can be attained neither by early nor by late learners as shown in Figure 3.

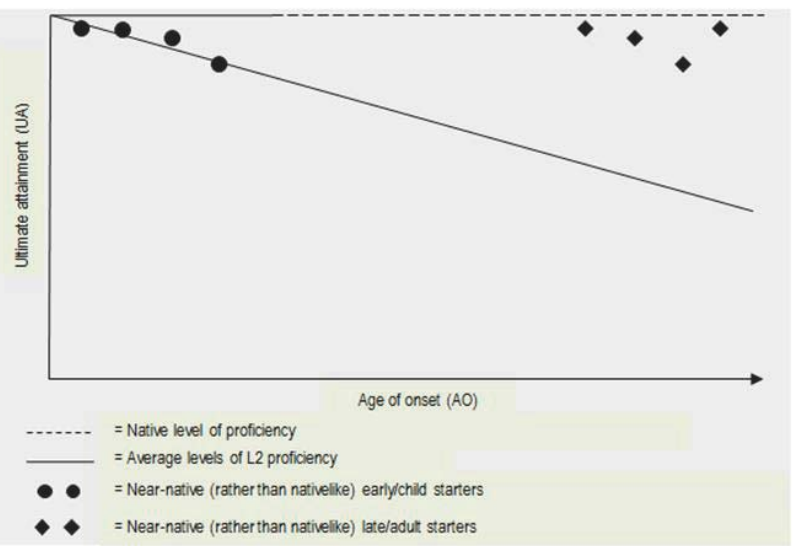

Figure 3. A reassessment of the nativelikeness of both early and late starters. "Maturational Constraints in SLA" by K. Hyltenstam and N. Abrahamsson, 2003, p. 569. From The Handbook of Second Language Acquisition by Long, M. H. , 2003, Oxford, UK: Blackwell Publishing Ltd.

This theory is based on evidences which prove that even early learners cannot match native speakers (Ekberg, 1998; Hene, 1993; Hyltenstam, 1992; Hyltenstam and Abrahamsson, in print, McDonald, 2000 in Hyltenstam and Abrahamsson, 2003), that the ultimate attainment of some extremely successful older learners shown in Figure 3 is not identical in all relevant aspects to that of native speakers (Coppiertes, 1987; loup et al, 1994; Moyer, 1999; White and Genesee, 1996 in Hyltenstam and Abrahamsson, 2003) or that ultimate attainment declines linearly (not suddenly) with age (Bialystok and Hakuta, 1999; Birdsong, 1999; Butler, 2000; Flege, 1999; Guion et al, 2000 in Hyltenstam and Abrahamsson, 2003). The first interpretation of this theory is that the possibility of second language ultimate attainment linearly declines already from the birth (Hyltenstam and Abrahamsson, 2003; Birdsong, 1999) and the second one suggests that the declined language skills result from a linear decline of all the skills in general (Bialystok and Hakuta, 1999 in Hyltenstam and Abrahamsson, 2003).

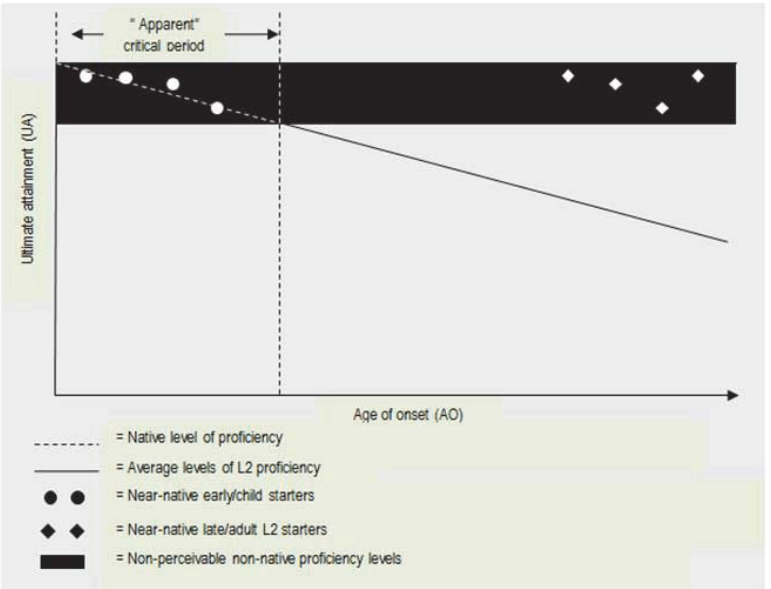

Figure 4. A reinterpretation of nativelikeness as non-perceivable non-nativeness, and the critical period as an "illusion" based on data from underanalyzed early starters. "Maturational Constraints in SLA" by K. Hyltenstam and N. Abrahamsson, 2003, p. 572. From The Handbook of Second Language Acquisition by Long, M. H. , 2003, Oxford, UK: Blackwell Publishing Ltd. 
Figure 4 encompasses all the previous theories and figures denoted by numbers 1,2 and 3 . The Figure 4 makes it clear that the examinees qualified as native speakers do not actually exist, i. e. the examinees identified as native speakers, who start learning a language early or some late learners, who were regarded as native speakers, are actually very close to the native speakers' level but not really on it. What is thought to be a critical period is nothing else but the time preceding the age of onset, whereas the ultimate attainment of average learners of a second language is claimed not to be on the native speakers' level.

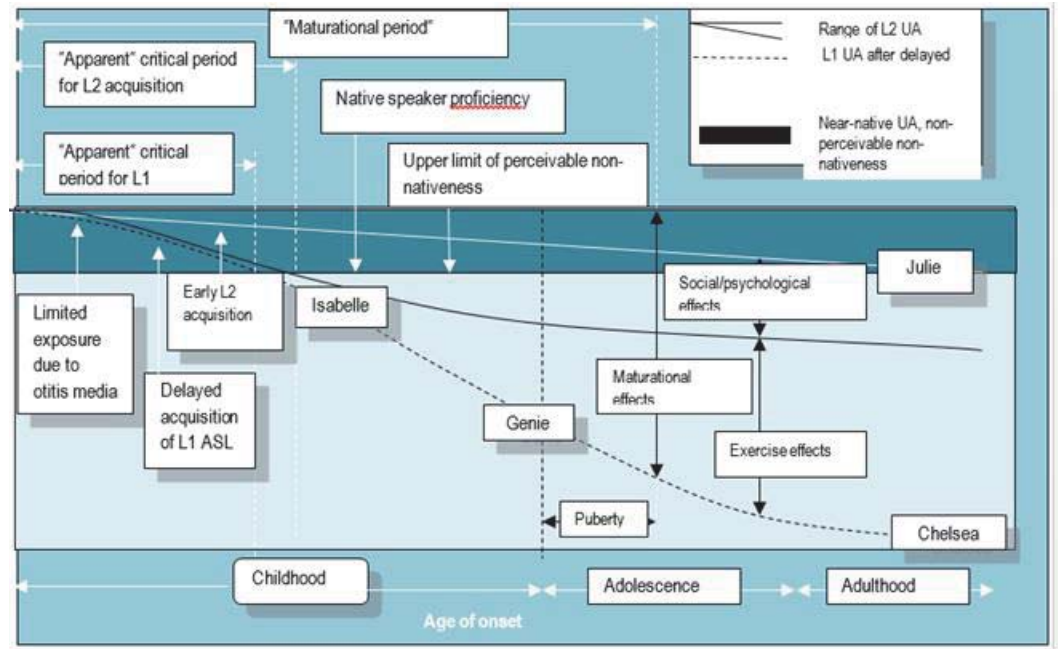

Figure 5. A model of the interplay between maturation, exercise, and social/psychological factors. "Maturational Constraints in SLA" by K. Hyltenstam and N. Abrahamsson, 2003, p. 573. From The Handbook of Second Language Acquisition by Long, M. H. , 2003, Oxford, UK: Blackwell Publishing Ltd.

Figure 5 actually presents a consensus model, the purpose of which is to integrate the existing empirical facts and various theories. Although maturation plays an important role in language acquisition, other factors also contribute to the ultimate attainment of some individuals. Figure 5 shows a possible scope of attainment levels which range from zero (bottom of the diagram) to ultimate attainment (on top). The black bold line in Figure 5 presents an attainment level similar to that of native speakers and the upper curve shows the ultimate outcome of some exceptionally successful individuals (Julie). The lower solid line presents the final achievement of students who cannot be regarded as successful students. The space between the two curves presents the range of the achieved attainment levels. The dotted curve presents the delayed attainment of the first language. Although cases of first language delayed attainment are rare, they still clearly show that the previously established system of first language delayed attainment influences second language attainment. The difference between the level of attainment of the native speakers and a low level of first language attainment is a reflection of the maturational effect, i. e. maturation can explain the general and linear decline of language acquisition, which rises with an increasing age of onset while the difference between exceptionally successful and unsuccessful learners with the same age of onset cannot be interpreted by maturation. In other words, sociopsychological factors can clarify the reasons why a learner who starts learning a language at the age of 25 is able to reach a higher level of attainment than another learner of the same age, but these factors cannot explain the reasons why a child who starts learning a language at the age of four has a better score than the older learner. The latter explanation can be provided only by maturational factors. It seems that the role of socio-psychological factors becomes extremely important later in life. At the age of six or seven, all the learners automatically attain levels which make them eligible to appear as native speakers - under the condition that there is a sufficient input and after that, sociopsychological factors have to be extremely favourable to compensate for the negative impacts of maturation.

Figure 5, similar to Figure 4, does not involve curves that reach the peak of the diagram; ultimate attainment cannot be achieved even if started only slightly later. Taking into account the fact that there are no proofs that any adult learner can match native speakers at all levels and considering the fact that early learners cannot catch up with native speakers either, one can draw the conclusion that complete second language mastering is not possible. 
Finally, the term maturational period itself (period between the birth and the $15^{\text {th }}$ year of life) is used instead of the term critical/sensitive/optimal period. The continuous decline of all the curves after the age of 15 can be interpreted as something that does not depend on maturational factors. Ultimate attainment depends on the level of motivation, talent and other potentials of a person which cannot be anticipated based on the age of onset. On the other hand, the critical period, based on attainment native speaker-like levels can be predicted if the attainment commences within the critical period. Figure 4 focuses on the importance of time periods which can be understood as critical periods. The bottom of the black bold line in Figure 5 is at the end interrupted (firstly by the curve that represents the first language and then by the lower curve that represents the second language). If the bottom of the line representing the native speaker-like attainment is interpreted as an ultimate attainment, identical to that of native speakers, it can be concluded that there are obvious critical periods within which a high level attainment similar to that of native speakers can be realized. Still, there is a pending question where (or how) the upper curve representing the second language passes the limit of the level which is below the native speakers' level. In line with the aforementioned, some studies dealing with the issue of the critical period can be challenged, even though there are evidences of the role of maturation in the first and second language acquisition.

\section{Conclusion}

There are few scientists today who deny the long-lasting advantage of children who start acquiring a second language as early starters. However, some discrepancies appear regarding the issue if this fact is to be explained by biological factors or limitations imposed on a learner together with maturational or socio-psychological factors.

If acquisition of a second language vastly results from conscious efforts, namely, from learning in formal circumstances, the advantages of an early onset are either not recognized or are dependent both on the age and many other factors. Therefore, the ultimate success in second language learning is attributed to the interaction of a number of factors - motivational, interlingual, educational, cognitive and affective, satisfaction with the achievement, and a positive attitude towards all novelties.

\section{References}

Birdsong, D. (1999). Second Language Acquisition and the Critical Period Hypothesis. Mahwah, NJ: Lawrence Erlbaum Associates, Inc. DeKeyser, R. M. (2000). The robustness of critical period effects in second language acquisition. SSLA, 22, 499-533.

Dimroth, C. (2008). Age Effects on the Process of L2 Acquisition? Evidence from the Acquisition of Negation and Finiteness in L2 German. Language Learning, 58 (1), 117-150.

Dong, G. \& Ren, H. (2013). The Role of Age in Second Language Acquisition - A Psychological Perspective. British Journal of English Linguistics, 1 (1), 1-6.

Harley, B. (1986). Age in Second Language Acquisition. Clevedon: Multilingual Matters Ltd.

Hyltenstam, K. \& Abrahamsson, N. (2000). Who can become native-like in a second language? All, some, or none? On the maturational constraints controversy in second language acquisition. Studia Linguistica, 54 (2), 150-166.

Hyltenstam, K. \& Abrahamsson, N. (2003). Maturational Constraints in SLA. In Doughty, C. J. \& Long, M. H. (Eds. ), The Handbook of Second Language Acquisition. pp. 539-588. Oxford, UK: Blackwell Publishing Ltd.

Hyltenstam, K. \& Abrahamsson, N. (in print): Age of onset and ultimate attainment in near-native speakers of Swedish. In Doughty, C. J. \& Long, M. H. (Eds. ), The Handbook of Second Language Acquisition. Oxford, UK: Blackwell Publishing Ltd.

Johnson, J. S. , \& Newport, E. L. (1989). Critical Period effects in second language learning: the influence of maturational state on the acquisition of English as a second language. Cognitive Psychology, 21 (1), 60-99.

Krashen, S. , Long, M. H. \& Scarcella, R. (1979). Age, rate and eventual attainment in second language acquisition. TESOL Quaterly. $13(4), 573-82$.

Lenneberg, E. H. (1967). Biological Foundations of Language. New York: Wiley.

Medved Krajnović, M. (2010). Od jednojezičnosti do višejezičnosti. Zagreb: Leykam international.

Moyer, A. (2004). Age, Accent and Experience in Second Language Acquisition. Clevedon, Buffalo, Toronto: Multilingual Matters.

Newport, E. L. (1990). Maturational constraints on language learning. Cognitive Science, 14 (1), 11-28.

Nikolov, M. (2009). Early Learning of Modern Foreign Languages: Processes and Outcomes. Bristol/Buffalo/Toronto: Multingual Matters.

Singleton, D. (1989). Language Acquisition: the Age Factor. Clevedon, Avon: Multilingual Matters.

Singleton, D. (2005). The critical period hypothesis: A coat of many colours. International Review of Applied Linguistics,43, $269-286$.

Singleton, D. \& Ryan, L. (2004). Language Acquisition. The Age Factor. 2nd edition. Clevedon, Buffalo, Toronto: Multilingual Matters Ltd. 
